\title{
Double Volvulus, Transverse Colon and Sigmoid at Kati Chu BSS: About 2 Cases
}

\author{
Koniba Keita $^{1^{*}}$, Abdoulaye Diarra1, Sidiki Keita ${ }^{2}$, Fodé Mory Keita1, Oulematou Coulibaly ${ }^{3}$, \\ Amadou Traoré ${ }^{4}$, Assitan Kone1, Salia Coulibaly5 ${ }^{5}$ Aimé Christophe Dembélé1, Oumou Koné1, \\ Birama Togola6, Daouda Diallo7, Boubacar Kone1, Drissa Traoré6, Bacary T. Dembélé4
}

\author{
${ }^{1}$ General Surgery Department, Hospital BSS, Kati, Mali \\ ${ }^{2}$ General Surgery “A” Department, Hospital Point-G, Bamako, Mali \\ ${ }^{3}$ Reference Heath Centre of the Commune VI, Bamako, Mali \\ ${ }^{4}$ General Surgery Department, Hospital Gabriel Touré, Bamako, Mali \\ ${ }^{5}$ Medical Imaging Department, Hospital BSS, Kati, Mali \\ ${ }^{6}$ General Surgery “B” Department, Hospital Point-G, Bamako, Mali \\ ${ }^{7}$ Anesthesia Resuscitation Department, Hospital BSS, Kati, Mali \\ Email: *konibakeita91@gmail.com
}

How to cite this paper: Keita, K., Diarra, A., Keita, S., Keita, F.M., Coulibaly, O., Traoré, A., Kone, A., Coulibaly, S., Dembélé, A.C., Koné, O., Togola, B., Diallo, D., Kone, B., Traoré, D. and Dembélé, B.T. (2021) Double Volvulus, Transverse Colon and Sigmoid at Kati Chu BSS: About 2 Cases. Surgical Science, 12, 296301.

https://doi.org/10.4236/ss.2021.128030

Received: July 22, 2021

Accepted: August 23, 2021

Published: August 26, 2021

Copyright $\odot 2021$ by author(s) and Scientific Research Publishing Inc. This work is licensed under the Creative Commons Attribution-NonCommercial International License (CC BY-NC 4.0). http://creativecommons.org/licenses/by-nc/4.0/

c) (1) () Open Access

\begin{abstract}
The simultaneous double volvulus of the transverse colon and sigmoid in the same patient is a rare cause of intestinal occlusion. Two cases were observed in general surgery in Kati. Its clinical symptomatology does not differ from other occlusions as well as simple radiological images. It is an extreme surgical emergency, the diagnosis is generally intraoperative. Extensive left hemicolectomy with terminoterminal rectal anastomosis was performed. The surgical follow-up was simple.
\end{abstract}

\section{Keywords}

Volvulus, Transverse, Sigmoïde, Surgery, Colon

\section{Introduction}

The term volvulus derives from the Latin "volvere" which means a twist [1]. The volvulus of the colon is therefore a torsion of the large intestine around its axis causing a mechanical occlusion by strangulation. When this phenomenon occurs synchronously at two different levels of the colic segment, it is called double volvulus. According to Lianos and collaborators [2], the sites of predilection for colon volvulus are in order of decay the sigmoid colon (75\%), the caecom (22\%), the transverse (2\%), and the splenic angle ( $1 \%$ to $2 \%)$. If the volvulus of the sigmoid colon is common that of the transverse is rare [3]. However, the syn- 
chronous occurrence of these two volvulus is a rarer entity of the colic occlusions [4] [5]. We report for the first time two cases of synchronous volvulus of the transverse and sigmoid colon in two men at the CHU BSS of Kati.

\section{Observation 1}

A 30-year-old rural male was returned to hospital for occlusive syndrome. At the anamnesis, the patient reported having sudden abdominal pain three days earlier with a stop of materials and gases, abdominal distension associated with food vomiting then meconials. In his history, he reports having episodes of chronic constipation accompanied by flatulence, intermittent abdominal pain yielding under traditional treatment based on herbal decoction. On examination we observed a general state classified stage 2 of the WHO (World Health Organization), an important asymmetric abdominal meteorism. Sunken eyes and dry tongue denote signs of dehydration. Blood pressure was $90 / 100 \mathrm{~mm}$ of mercury at $37.6^{\circ} \mathrm{C}$. Percussion-sensitive tympanism associated with rectal blister voidness. The X-ray of the abdomen without preparation (ASP) (Figure 1) showed colic distension in the form of double crescents higher than wide, with two jambs down in the pelvis.

The diagnosis of volvulus of the sigmoid colon was made. The requested biological check-up came back normal. The patient underwent emergency surgery after short resuscitation (infusion of crystalloids and macromolecules). The pubic xypho median laparotomy made it possible to objectify a double colic loop. One depends on the transverse colon, rotated around its centre line in a clockwise direction, and the other on the sigmoid colon in a clockwise direction, giving the image of double volvulus of the transverse colon and the sigmoid (Figure 2). The two colic loops were not necrotic and each was at a turn of the spire. We proceeded to a rapid devollvulation of the two loops and proceeded to an extended left hemicolectomy with terminoterminal colorectal anastomosis. The aftercare was laced with diarrhea. The patient was released on day 12. After a three-month decline, the patients were reviewed. They reported a decrease in bowel movements to 2 to 3 times a day. After a 12 months follow-up, we lost sight of the patient.

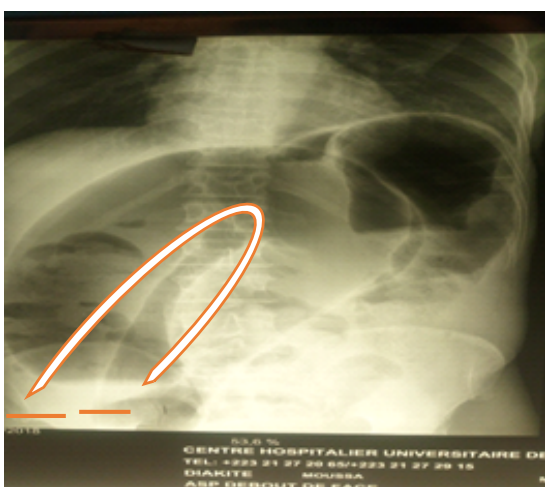

Figure 1. X-Ray Overturned " $U$ " 2 hydro-aeric levels. 


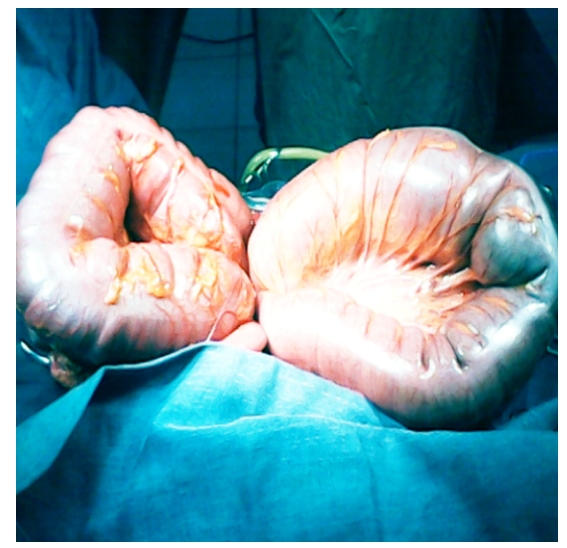

Figure 2. Double volvulus transverse colon and sigmoidn and sigmoid (Case 1).

\section{Observation 2}

A 62-year-old man admitted to the emergency department of the Kati Hospital Hospital for painful abdominal distension with vomiting and cessation of materials and gases for 48 hours. To the anamnesis He reports being constantly constipated and with episodes of painful meteorism yielding spontaneously with flatulence for years. At the clinical examination the blood pressure was 100/80 millimetres of mercury, the temperature was $36.7^{\circ} \mathrm{C}$. The overall condition of the patient was rated 2 at the WHO level. On the physical examination, there was an asymmetrical abdominal distension, painful on palpation, with a hyper sonority on percussion. The rectal vial was empty with no intraluminal mass. At the ASP we observed a large dilatation of the colon in the form of an overturned " $U$ " with two hydro-aeric levels in the pelvis. The diagnosis of pelvic colon volvulus was retained. The biological assessment made it possible to objectify a haemoglobin level at $10 \mathrm{~g} / \mathrm{dl}$, the white blood cells were at 9100 elements $/ \mathrm{mm}^{3}$, blood sugar at 6 milli moles per litre and creatinine at 95 micromoles per litre. After a short resuscitation of 3 hours of time with infusion of crystalloids and macromolecules, the patient was transferred to the operating room. At laparotomy, the exploration discovers two colic loops without necrosis, one on the transverse colon at a turn of the spire in the anticlockwise direction and the other at the sigmoid colon at a turn of the spire also in the clockwise direction (Figure 3). After a double devolution, the colon was abnormally long and large (megacolon dolicho), we proceeded to an extended left hemicolectomy with terminoterminal colorectal anastomosis. The aftercare was stained with diarrhea and the patient was released on day 14 .

After a three-month decline, the patients were reviewed. They reported a decrease in bowel movements to 2 to 3 times a day. After a 6 months follow-up, we lost sight of the patient.

\section{Discussion}

The double volvulus of the colon is a rare. Today, no author has reported more 


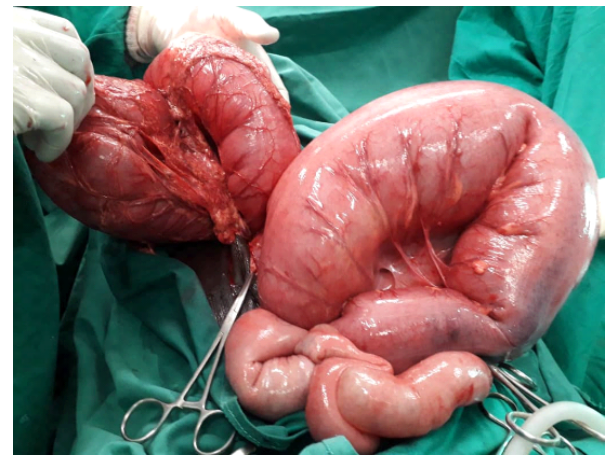

Figure 3. Double volvulus transverse colon and sigmoid (Case 2).

than two cases in African series. It is a first that an author reports two cases of synchronous double volvulus involving the transverse colon and the sigmoid in the literature. This is an extreme surgical emergency with the risk of double necrosis. In the service the colon volvulus represents $37.2 \%$ of intestinal occlusions with a mortality of $2.86 \%$ [6].

While Islam Shari [4] and Nicholas TM [7] reported significant comorbidities in their patients (stroke, systemic lupus erythematosus, scleroderma, diabetes, leg vasculitis or even hypothyroidism), our patients had a stage 1 overall condition at the WHO (World Health Organization) level. Besides, they had never been operated on before. In addition, our patients reported a notion of chronic constipation, episodic abdominal pain with significant flatulence as reported by authors [2] [8]. Certain etiological factors of volvulus such as megacolon dolicho, chronic constipation, excessive mobility or lack of fixation of the right colon or splenic angle, shortening of the meso colon have always been found in the genesis of this pathology [1]. Both patients reported chronic constipation, flatulence, and laparotomy had excessive mobility of the colon, a megacolon dolicho. The unprepared abdominal radiograph made it possible to diagnose the sigmoid colon volvulus under a huge colic distension (gas crescent) in " $U$ " inverted with the two jambs in the pelvis (Figure 1). However the diagnosis of synchronous double volvulus of the transverse colon and sigmoid was made in intraoperative. The authors made the same remarks during laparotomy [2] [3] [4]. In this respect, it is the scanner which makes it possible to make the diagnosis of double volvulus of the colon with precision as reported by Nicholas TM [7] in his observation. It not only makes it possible to establish the etiological and topographic diagnosis but also to prejudge the viability of occluded handles; it is the reference examination.

If endoscopic colo-exsufflation followed by surgery is the consensual therapeutic approach in developed countries [4], the direct surgical approach is most commonly used for several reasons: patients arrive in hospitals at the stage of complications, the financial problem, the lack of endoscopy technical tray in our structures. The treatment consisted of a double devolvulation (transverse colon and sigmoid) followed by an extended left hemicolectomy followed by a terminoterminal 
colorectal anastomosis. This was justified by the fact that the handles were not necrotic, the patients were hemodynamically stable and they were not old people with fat. In Morocco, Abderrahim S [5] had the same therapeutic attitude. However, Abdourahamane N'Dong [9] preferred the left hemicolectomy with colostomy given the advanced age of his 74-year-old patient. We believe that the left hemicolectomy with colorectal anastomosis in one time would be the right technique provided that the loop is not necrotic, that the patient is hemodynamically stable and not very advanced in age. On the other hand, in case of necrosis of the handle and in old people, the left colectomy with colostomy will be preferred. This technique not only corrects colic redundancy, shortens the colon and therefore treats constipation. A total colectomy would lead to malnutrition of the patient that will threaten his survival [2]. The occluded segment resection with double anastomoses in emergency on an unprepared colon as in Kambiré JL [10] exposes to a lot of morbidities (fistula, sepsis) see death. We did not observe any deaths unlike Kambiré JL [11] and Wissam JH [11].

\section{Conclusion}

The simultaneous double volvulus of the transverse colon and sigmoid is a rare surgical emergency. Extended left hemicolectomy with colorectal anastomosis is preferable if the patient is hemodynamically stable and in the absence of colic necrosis.

\section{Conflicts of Interest}

The authors declare no conflicts of interest regarding the publication of this paper.

We have obtained the consent of patients for the publication of these cases.

\section{References}

[1] Ballantyne, G.H. (1982) Review of Sigmoid Volvulus: History and Treatment Outcomes. Diseases of the Colon \& Rectum, 25, 494-501. https://doi.org/10.1007/BF02553666

[2] Lianos, G., Ignantiadou, E., Lianou, E., et al. (2012) Simultaneous Volvulus of the Transverse and Sigmoid Colon: Case Report. G. Chir, 33, 324-326.

[3] Halabi, W.J., Jafari, M.D., Kang, C.Y., et al. (2014) Colic Volvulus in the United States: Trends, Outcomes and Predictors of Mortality. Annals of Surgery, 259, 293-301. https://doi.org/10.1097/SLA.0b013e31828c88ac

[4] Islam, S., Devin, H., Vinoo, B. and Dilip, D. (2016) Synchronous Volvulus of the Sigmoid Colon and Caecum, a Very Rare Cause of Large Bowel Obstruction. BJM Case Report. https://doi.org/10.1136/bcr-2016-217116

[5] Abdderrahim, S., Saïd, B., Asma, H., Youssef, N. and Ridouan, B.B. (2021) Synchronous Volvulus of the Transverse and Sigmoid Colon: A Rare Case of Occlusion of the Large Intestine. Pan-African Medical Review, 8, 231.

[6] Keita, K., Diarra, A., Coulibaly, S., Keita, S., Traore, I., Doumbia, M., et al. (2019) Sigmoid Colon Volvulus: Surgical Management at Kati BSS Hospital (Mali). Surgical Science, 10, 76-82. https://doi.org/10.4236/ss.2019.103010 
[7] Nicholas T. Manasewitsch B.S., Michael T. Lee B.S. and Anthony N. Khuu M.D., M.B.A. (2021) Synchronous Volvulus of the Transverse Colon and Coecum Associated with Scleroderma and Lupus. Radiology Case Reports, 16, 273-277. https://doi.org/10.1016/j.radcr.2020.11.020

[8] Elsharif, M., Basu, I. and Phillips, D. (2012) A Case of Triple Volvulus. Annals of The Royal College of Surgeons of England, 94, e62-e64.

https://doi.org/10.1308/003588412X13171221500781

[9] Ndong, A., Diao, M.L., Tendeng, J.N., Diallo, A.C., Nyemb, P.M.M. and Konaté, I. (2020) Synchronous and Transverse Sigmoid Volvulus: About a Case and Qualitative Systematic Review. International Journal of Surgery Case Reports, 75, 297-301. https://doi.org/10.1016/j.ijscr.2020.09.027

[10] Kambiré, J.L., Ouédrago, S., Ouédrago, S. and Zida, M. (2021) Synchronous Volvulus of the Sigmoid and Transverse Colon. Jaccra Africa, 5, 186-189.

[11] Wissan, J.L., Mehraneh, D.J., Celeste, Y.K., et al. (2014) Volvulus United States: Trends, Outcomes and Predictors of Mortality. Annals of Surgery, 259, 293-301. 